\title{
ARRANQUE DE UN REACTOR UASB PARA EL TRATAMIENTO DE AGUAS RESIDUALES DOMÉSTICAS EN CONDICIONES ANDINO AMAZÓNICAS
}

Fecha de recepción: 05 de septiembre de 2014 • Fecha de aceptación: 28 de octubre de 2014

\section{START-UP A UASB REACTOR FOR DOMESTIC WASTEWATER TREATMENT IN ANDEAN-AMAZONIAN CONDITIONS}

César Augusto Orozco Gaviria', Cristian Camilo Triviño Cabrera², Lis Manrique Losada ${ }^{3,4}$

\section{RESUMEN}

La presente investigación consistió en determinar las condiciones de arranque y operación de un reactor anaerobio tipo UASB a escala laboratorio en la región Andino Amazónica para el tratamiento de aguas residuales domésticas (ARD). Para el arranque se establecieron dos etapas, la primera etapa consistió en definir el caudal que el reactor soportaba sin fluidización del lecho y que ofreciera la mayor remoción de materia orgánica, para este fin se definieron 3 fases a diferente caudal empezando por el menor de ellos. Posteriormente, con un caudal definido se aplicó la segunda etapa para definir la concentración del ARD donde el reactor funcione mejor y remueva mayor concentración de materia orgánica, se trabajó a una concentración de sustrato (150-200 mg.L-1 y 300-400 m.L-1) con el caudal seleccionado en la etapa 1. Se implementaron tres tipos de monitoreo para el proceso anaerobio: monitoreo de estabilidad, eficiencia para el sustrato, calidad y cantidad del lodo anaerobio. El sistema trabajó con buenos resultados en cuanto a parámetros fisicoquímicos y biológicos a caudal de 206,7 mL.h ${ }^{-1}$ con tiempo de residencia hidráulica (TRH) de 25.28 h. Se obtuvieron porcentajes de remoción de materia orgánica superiores al 70\% y remoción de coliformes tanto totales como fecales de un $24 \%$ en el ARD a concentración media y alta de sustrato, como también valores de pH cercanos a la neutralidad y producción de metano. Los resultados indican que se puede implementar un reactor tipo UASB en condiciones Andino-Amazónicas, con concentraciones de DQO de un ARD, por encima de 300 mg. L-1.

Palabras claves: Tratamiento de aguas residuales, Digestión anaerobia, Reactores UASB, Actividad metanogénica específica, Granulometría, Tiempo de residencia hidráulica.

1 Laboratorio de Fisicoquímica de Aguas, Facultad de Ciencias Básicas, Universidad de la Amazonia. Florencia Caquetá.

2 Laboratorio de Fisicoquímica de Aguas, Facultad de Ciencias Básicas, Universidad de la Amazonia. Florencia Caquetá.

3 M.Sc. Ingeniera Química, Docente investigadora, Líder Grupo Materiales, Ambiente y Desarrollo MADE. Facultad de Ciencias Básicas. Universidad de la Amazonia.

4 Autor Corresponsal: lismanrique@gmail.com. 


\begin{abstract}
The aim of this study is to determine the appropriate conditions to start and operate an anaerobic UASB reactor at pilot scale in Andean-Amazonian conditions for the treatment of domestic wastewater (DW). The starting conditions were established by varying flow rate average concentration of the substrate, $280-300 \mathrm{mg} . \mathrm{L}$ ${ }^{1}$, and for the operations phase substrate concentration (150-200 mg. $\mathrm{L}^{-1}$ an d 300 was varied $-400 \mathrm{~mL}^{-1}$ ). Three types of monitoring for anaerobic process were implemented: Stability control, substrate efficiency, quality and quantity of anaerobic sludge. For $206.7 \mathrm{~mL} . \mathrm{h}^{-1}$ hydraulic residence time (HRT) of $25.28 \mathrm{~h}$ the system show good physicochemical and biological results. Percentages of organic matter removal are greater than $70 \%$ and for both total coliforms and fecal $24 \%$ when the DW has a medium and high substrate concentration, as well as, $\mathrm{pH}$ values almost neutral and methane production was obtained. The results indicate that it can easily start a UASB reactor in Andean-Amazonian conditions, except when working with very dilute DW.
\end{abstract}

Keywords: Wastewater treatment, anaerobic digestion, UASB reactors, specific methanogenic activity (SMA), Particle size distribution, hydraulic residence time (HRT).

\title{
INTRODUCCIÓN
}

Un bajo porcentaje de las aguas residuales domésticas de los países en desarrollo, son sometidas a tratamiento antes de ser dispuestas sobre ecosistemas acuáticos. Esta situación se debe principalmente a aspectos financieros y al desconocimiento de tecnologías sostenibles. Dentro de los diferentes sistemas de tratamiento de bajo costo disponibles actualmente está la digestión anaerobia, siendo una tecnología clave que genera subproductos con valor agregado (bioenergía, nutrientes y agua para reúso) (Torres, 2012) y son eficientes en regiones de clima tropical y subtropical (temperaturas superiores a $20^{\circ} \mathrm{C}$ ).

El proceso de tratamiento de aguas residuales, tipo anaerobio se caracteriza por la conversión completa de los contaminantes orgánicos en el agua residual, a una mezcla de gases como el $\mathrm{CH}_{4} \mathrm{CO}_{2}, \mathrm{H}_{2}$ y $\mathrm{H}_{2} \mathrm{~S}$ producto de la digestión anaerobia de las bacterias presentes en el lodo y que interactúan con el agua residual a tratar. Este proceso debe estar equilibrado para evitar la acumulación de los ácidos grasos volátiles y por tanto impedir una repentina caída en el pH del sistema, que puede conducir a un fallo completo del proceso de conversión de digestión anaerobia, puesto que el sistema debe contener mayoritariamente bacterias metanogénicas y no acidogénicas (Molina et al, 2009).

Durante el arranque y operación de los reactores anaerobios se recomienda el seguimiento de algunos parámetros fisicoquímicos y el uso de algunas herramientas que permitan evaluar su desempeño. Según (Chernicharo, 2007; Pérez y Torres, 2010) el monitoreo de los sistemas anaerobios puede agruparse en tres tipos:

El monitoreo de la eficiencia que busca establecer el comportamiento de la unidad y su desempeño frente a las especificaciones de diseño. Medición de parámetros como Sólidos Suspendidos Totales, Demanda Química de Oxígeno (DQO), Demanda Bioquímica de Oxígeno (BDO) y Organismos patógenos. 
El monitoreo de la estabilidad tiene como objetivo evaluar la prevalencia de la fermentación acidogénica sobre la metanogénica que puede ocasionar la acidificación del sistema. Consiste en la medición de pH, Ácidos Grasos Volátiles (AGV), Alcalinidad (Total, Parcial y debida a AGV), Índices de Alcalinidad (Buffer, Al/AP y Al/AT) (Pérez y Torres, 2010) y Composición del biogás (incremento del $\mathrm{CO}_{2}$ ).

El monitoreo de la cantidad y calidad del lodo, consiste en evaluar Sólidos Totales (ST) y Sólidos Volátiles Totales (SVT) como características cuantitativas del lodo y evaluar los aspectos cualitativos con herramientas como la Actividad Metanogénica Específica (AME), ensayos de Índice Volumétrico de Lodos (IVL), Velocidad de Sedimentación (VS) y Granulometría.

Según Morillo y Fajardo (2005) hay tres tipos de lodo: disperso, debido a que no hay agregación de partículas en el lodo (velocidad de sedimentación $0.05-0.2 \mathrm{~m} / \mathrm{h}$ ), floculento, que consiste de un agregado en flóculos sueltos con propiedades intermedias de sedimentación ( $\left.2 \mathrm{~m} \cdot \mathrm{h}^{-1}\right)$ y granular representado en gránulos compactos de 0.5 a $3 \mathrm{~mm}$ de diámetro (velocidad media de sedimentación $50 \mathrm{~m} \cdot \mathrm{h}^{-1}$ ).

El sistema Anaerobio, está atrayendo cada vez más la atención de los ingenieros sanitarios y gobernantes. Donde el Upflow Anaerobic Sludge Bed or Blanket (UASB) o reactor de flujo ascendente anaerobio de lecho o manto de lodos, está siendo utilizado con éxito en los países tropicales, dando resultados alentadores en las regiones subtropicales y templadas (Seghezzo, 2004).

El reactor UASB desarrollado por Gatze Lettinga (1970), consta de dos partes: una columna cilíndrica o rectangular y una (GLS) separador gas-líquidosólido (Lettinga y Hulshoff, 1991; Hulshoff et al. 2004; Chong et al, 2012). Los lodos se encuentran en la parte inferior del reactor en condiciones apropiadas para la formación de flóculos o gránulos que consiste de materias inertes, inorgánicas y orgánicas con pequeños agregados bacterianos en el lodo de semillas. Después de un cierto período (por lo general 2-8 meses), dependiendo de las condiciones de operación y las características de las aguas residuales y lodos de semillas, el lecho de lodo se vuelve denso, de tal forma que puede ser granular o floculento con propiedades de alta sedimentación (Chong et al, 2012).

Las aguas residuales del Municipio de Florencia-Caquetá son descargadas directamente sobre el río Hacha; las quebradas El Dedo, La Sardina, y La Perdiz; los humedales San Luis y Versalles, (Corpoamazonia, 2002). Las condiciones climáticas del municipio de Florencia son de tipo cálido-húmedo, característico del ecosistema de bosque húmedo tropical. La ciudad está ubicada a 242 msnm, cuenta con una temperatura media anual de 25 a $30^{\circ} \mathrm{C}$, con una tendencia monomodal (Iluvias) a lo largo del año (Instituto Sinchi, 2006), lo cual es perfecto para la implementación de un reactor anaerobio tipo UASB.

En esta investigación se da a conocer el arranque de un reactor UASB a escala laboratorio en condiciones Andino-Amazónicas para el tratamiento del agua residual doméstica que se genera en el municipio de Florencia-Caquetá.

\section{MATERIALES Y MÉTODOS}

\section{Montaje reactor UASB}

Se empleó un reactor tipo UASB continuo a escala piloto, elaborado en acrílico de $3 \mathrm{~mm}$ de grosor, $6,35 \mathrm{~cm}$ de diámetro interno, $165 \mathrm{~cm}$ de altura, con un área de $31,67 \mathrm{~cm}^{2}$; equipado con un deflector y separador Gas-Liquido-Sólido (GLS). Contaba con un embudo de captación de gas secuenciado a un recipiente de neutralización con $\mathrm{NaOH}$ al 3\%, un sistema de acoplamiento para instalación de bomba peristáltica (Dolphin Series modelo 10-marca Pulsafeeder) como lo muestra la figura 1.

El inóculo utilizado consistió de una mezcla de estiércol de vaca y lodo anaerobio proveniente de 


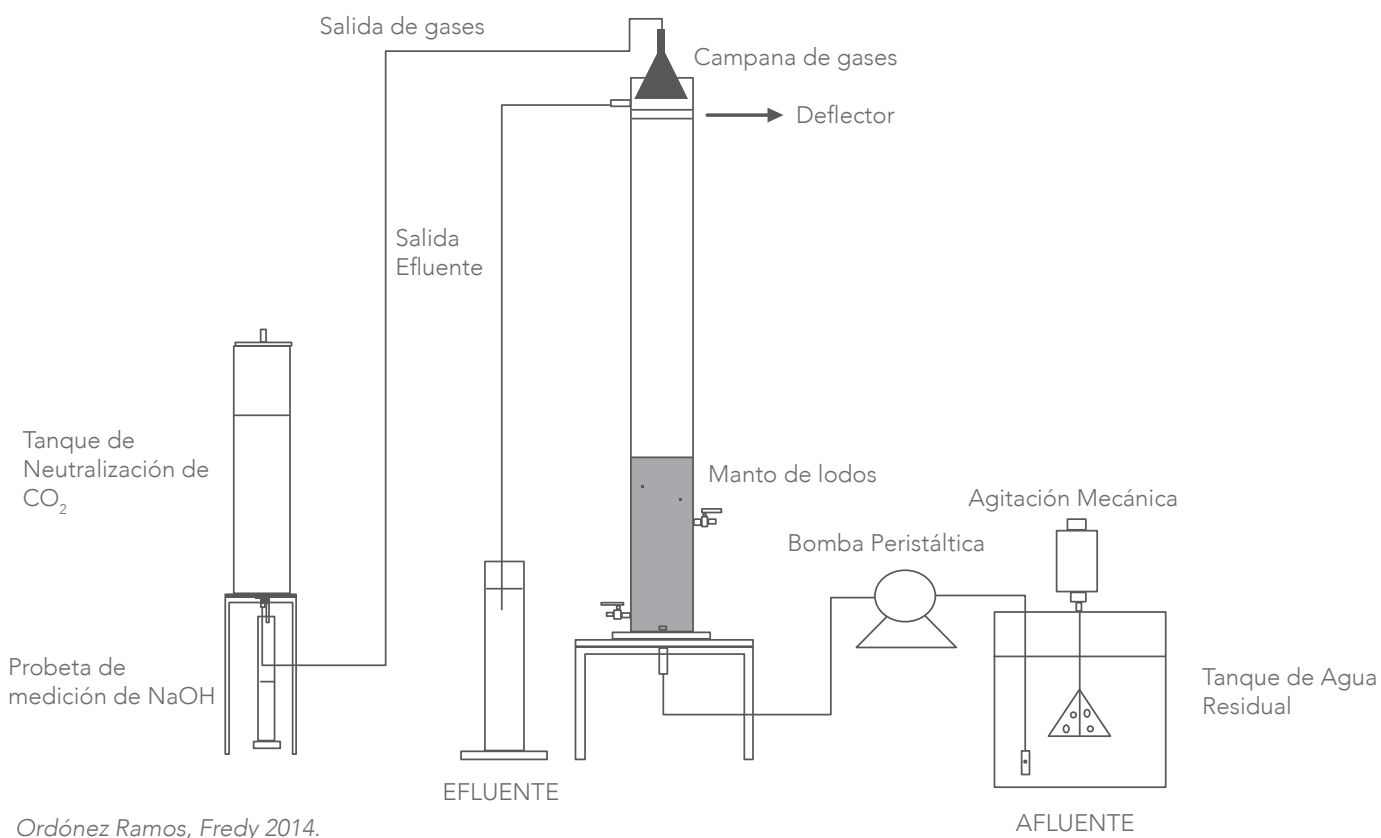

Figura 1. Reactor anaerobio UASB a escala piloto.

un digestor para tratamiento de aguas residuales domésticas con 5 años de funcionamiento. El agua residual doméstica (ARD) utilizada durante el proceso provenía de un box coulvert ubicado en el barrio San Francisco de la ciudad de Florencia Caquetá, donde transitan principalmente ARD.

El proceso se llevó a cabo en condiciones andino amazónicas, a temperatura ambiente que oscila entre 25 y $33^{\circ} \mathrm{C}$, humedades relativas desde $80 \%$ hasta $84 \%$ y sin control de $\mathrm{pH}$.

\section{Etapa de arranque}

El ARD inicial (afluente) se depositó en un tanque plástico con agitación mecánica y mediante bomba peristáltica se transportó el ARD para entrar por la parte inferior del tubo digestor, garantizando un tiempo de residencia hidráulica (TRH) determinado y haciendo contacto con el manto de lodos de $40 \mathrm{~cm}$ de altura, posteriormente el ARD salía por la parte alta del tubo digestor como efluente. El arranque consistió de dos etapas, en la primera se determinó un caudal adecuado para trabajar en el reactor, que no generara fluidización del lodo pero que mantuviera un máximo de remoción de materia orgánica (Tabla 1). Para este fin se utilizó un ARD a concentración media (280-300 mg. $\left.\mathrm{L}^{-1} \mathrm{DQO}\right)$, y se inició el arranque con un TRH de aproximadamente $35 \mathrm{~h}$, se determinó la eficiencia de remoción de DQO durante los días siguientes hasta que su valor estabilizó. Seguidamente se disminuyó el TRH hasta 25,28 h y se hizo el mismo seguimiento mencionado. Finalmente se pasó a la tercera fase con TRH de 21,164 h (mayor caudal) y se esperó estabilización del sistema. Con la información después del paso por las 3 fases, se definió un TRH óptimo para el reactor. En la segunda etapa se varió la concentración de DQO del afluente, desde aproximadamente 150200 mg. L ${ }^{-1}$ (concentración baja), hasta una DQO de 300-400 mg.L-1 (concentración alta), haciendo seguimiento de $\mathrm{DOO}$ cada día hasta estabilización de éste parámetro en el efluente del reactor. 
Tabla 1. Condiciones específicas durante la primera etapa del arranque

\begin{tabular}{cccc}
\hline \multirow{2}{*}{ VARIABLES } & \multicolumn{3}{c}{ FASES } \\
\cline { 2 - 4 } & $\mathbf{1}$ & $\mathbf{2}$ & $\mathbf{3}$ \\
\hline $\begin{array}{c}\text { Caudal } \\
\left(\mathbf{m L}^{-1}\right)\end{array}$ & 136,2 & 206,7 & 246,9 \\
\hline TRH (h) & 38.34 & 25.28 & 21.164 \\
\hline $\begin{array}{c}\text { Carga } \\
\text { orgánica } \\
\text { volumétrica } \\
\left(\mathbf{k g} \cdot \mathbf{m}^{-3} \text { * } \mathbf{d}\right)\end{array}$ & 0.1768 & 0.1909 & 0,2900 \\
\hline
\end{tabular}

\section{Seguimiento del proceso}

Para el afluente y efluente se realizaron análisis de DQO por el método de reflujo cerrado colorimétrico según APHA (2005), medición potenciométrica de $\mathrm{pH}$ (pH-metro marca HANNA HI 9812-5) y temperatura mediante, medición de la alcalinidad total (AT), parcial o debida al bicarbonato (AP) y alcalinidad intermedia (Al) debida a AGV por el método de Jenkins (1983), Por gravimetría (APHA, 1998) se determinaron los sólidos totales (ST) y sólidos totales volátiles (STV). Se determinaron los coliformes totales y fecales según Camacho et al. (2009).

En el lodo anaerobio se hizo seguimiento a la Velocidad de Sedimentación (VS); Índice Volumétrico de Lodos (IVL); granulometría de acuerdo a los procedimientos descritos por Díaz-Báez et al. (2002); sólidos totales, volátiles, coliformes totales y se determinó la actividad metanogénica especifica (AME) por el método de desplazamiento liquido (Diaz et al, 2002; Pérez y Torres, 2010).

\section{RESULTADOS Y DISCUSIÓN}

El desempeño del reactor UASB durante todo el período de arranque mostró una alta remoción de DQO en el efluente. Valores superiores al 70\% de remoción cuando se trabaja con un agua residual a concentración mayor de 250 mg. L-1 , valores superiores al 80\% de remoción de DQO a concentración alta de sustrato, bajos porcentajes de remoción de coliformes totales y fecales durante todo el proceso operacional de arranque, buen comportamiento de las formas de alcalinidad y del $\mathrm{pH}$ en el sistema, presentando una buena estabilidad cuando se trabajaba con aguas residuales a concentraciones medias y altas de DQO en el afluente.

La primera etapa del arranque, que consistió en tres fases con diferente TRH, generó resultados que demostraron la adaptación o aclimatación del lodo a las condiciones del agua y del ambiente, sin embargo en la fase 3, cuando se incrementó el caudal a 246,9 mL.h ${ }^{-1}$ (para un TRH de 21 d), el lodo se fluidizó hasta ocasionar taponamiento del reactor ocasionando pérdida de biomasa activa y fluctuación en los parámetros de estabilidad. Por tal razón, en esta fase no fue posible el seguimiento e inmediatamente se dio inicio a la segunda etapa con el caudal propuesto en la fase $2\left(206,7 \mathrm{~mL} \cdot \mathrm{h}^{-1}\right)$.

\section{Primera etapa del arranque}

La relación de AGV (Al) y la alcalinidad total debe ser considerada como una medida de la estabilidad de un proceso anaerobio, indicando un equilibrio entre acidogénesis y metanogénesis dentro del reactor (Turkdogan et al, 2011). Una buena operación del digestor anaerobio depende de una adecuada capacidad tampón del bicarbonato y de una no excesiva concentración de ácidos grasos volátiles, es adecuado usar un índice buffer (Al/AT) $\leq 0,3$, como parámetro de control (Molina, 2007). La Fig. 2 muestra la evolución del índice Buffer durante los días que duraba cada fase (determinado TRH según Tabla 1). Se observa que en las dos fases se mantiene el índice por debajo de 0,28, indicando una adecuada operación del reactor gracias a una óptima relación entre los AGV y la alcalinidad. 


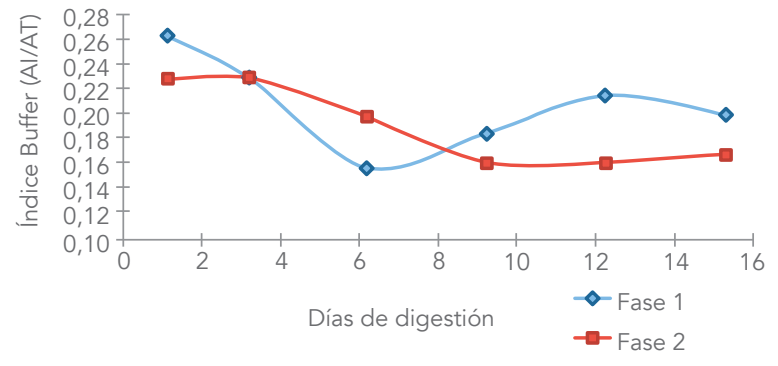

Figura 2. Capacidad tampón en el efluente después de la digestión anaerobia a concentración media de DQO.

Durante las fases de arranque del reactor la alcalinidad tuvo una variación normal y esperada para este tipo de sistemas (Tabla 2). AT del efluente en la fase 1, siempre fue mayor que la del afluente, debido a que el sistema busca generar iones bicarbonato en el afán de alcanzar el equilibrio con capacidad amortiguadora.

La alcalinidad depende de la relación de concentraciones de varios compuestos, tales como carbonato/bicarbonato, fosfato, amoníaco y ácidos grasos volátiles, que imparten capacidad tampón donde se genera un equilibrio gas carbónico/alcalinidad debido a que se tiende a regular la concentración de hidrógenos (Cajigas et al., 2005), como lo muestran las siguientes reacciones (Pérez y Torres, 2008).

$$
\begin{gathered}
\mathrm{CO}_{2}+\mathrm{H}_{2} \mathrm{O} \leftrightarrow \mathrm{H}_{2} \mathrm{CO}_{3} \leftrightarrow \mathrm{HCO}_{3}^{-}+\mathrm{H}^{+} \text {Ec. } 1 . \\
\mathrm{HCO}_{3}^{-}+\mathrm{OH}^{-} \leftrightarrow \mathrm{CO}_{3}^{2-}+\mathrm{H}_{2} \mathrm{O} \text { Ec. } 2
\end{gathered}
$$$$
\mathrm{HA}+\mathrm{NaHCO}_{3} \leftrightarrow \mathrm{NaA}+\mathrm{H}_{2} \mathrm{O}+\mathrm{CO}_{2} \text { Ec. } 3
$$

Donde: HA es el ácido graso volátil.

Las alcalinidades total y parcial presentan buen comportamiento por la baja producción de AVG (alcalinidad intermedia, Al), generando así una baja generación de $\mathrm{CO}_{2}$, evitando un exceso de iones hidronios que causan la acidificación en los ambientes anaerobios (Tabla 2, ecuación 3). Claramente se puede observar un mejor comportamiento de la alcalinidad en el agua residual operada durante la fase 2 a concentración media. Los valores de alcalinidad total, parcial e intermedia son más estables con relación al proceso realizado durante la etapa de arranque a fase 1.

Tabla 2. Alcalinidad total, parcial e intermedia a fase 1 y 2 antes y después de degradación anaerobia a concentración media.

Alcalinidad a concentración media $\mathrm{mgCaCO}_{3} \cdot \mathrm{L}^{-1}-$ Fase 1

\begin{tabular}{cccccc}
\hline \multicolumn{3}{c}{ Afluente } & \multicolumn{3}{c}{ Efluente } \\
\hline AP & AT & Al & AP & AT & Al \\
\hline $\mathbf{7 0 , 7 5}$ & 100,75 & 30 & 125,26 & 170,40 & 45,14 \\
\hline $\mathbf{8 8 , 0 0}$ & 123,00 & 35 & 120 & 156,25 & 36,25 \\
\hline $\mathbf{1 0 5 , 0 0}$ & 128,75 & 23,75 & 120 & 142,50 & 22,50 \\
\hline $\mathbf{1 0 3 , 3 3}$ & 129,16 & 25,83 & 113 & 138,79 & 25,79 \\
\hline $\mathbf{9 4 , 3 8}$ & 117,50 & 23,125 & 103,75 & 132,50 & 28,75 \\
\hline $\mathbf{9 7 , 5 0}$ & 115,00 & 17,5 & 103,89 & 130,12 & 26,23 \\
\hline
\end{tabular}

$\mathrm{mgCaCO}_{3} \cdot \mathrm{L}^{-1}$ - Fase 2

\begin{tabular}{cccccc}
\hline $\mathbf{A P}$ & AT & Al & AP & AT & Al \\
\hline $\mathbf{9 7 , 5}$ & 115 & 17,5 & 100 & 130 & 30 \\
\hline $\mathbf{1 0 0}$ & 127,5 & 27,5 & 100 & 130 & 30 \\
\hline $\mathbf{9 3 , 7 5}$ & 125,25 & 31,5 & 100 & 125 & 25 \\
\hline $\mathbf{9 8}$ & 123 & 25 & 103,33 & 123,33 & 20 \\
\hline $\mathbf{9 4}$ & 120 & 26 & 103,33 & 123,33 & 20 \\
\hline $\mathbf{9 5}$ & 122 & 27 & 103,33 & 124,33 & 21 \\
\hline
\end{tabular}

AP: Alcalinidad Parcial; AT: Alcalinidad Total; Al: Alcalinidad intermedia o debida a AGV. 
La Figura 3, demuestra que el $\mathrm{pH}$, con temperatura promedio de $27^{\circ} \mathrm{C}$, durante la primera etapa del arranque en sus fases 1 y 2 , se ajusta a los valores recomendados en la literatura y los datos obtenidos reflejan un buen comportamiento por parte del sistema cuando se está trabajando el reactor a esta concentración de sustrato, debido a que también existe una buena capacidad buffer (Fig. 2) donde no supera el 0.3 de relación (Al/AT).

No se observan diferencias significativas en el $\mathrm{pH}$ del efluente cuando éste sufre un incremento en el caudal (menor TRH). Se evidencia la tendencia del $\mathrm{pH}$ hacia un valor de 7 después de los 4 primeros días en cada fase.

De acuerdo con Lahav et al. (2002) y Molina et al. (2008), el funcionamiento exitoso de la degradación anaerobia requiere mantenimiento del $\mathrm{pH}$ en el sistema entre 6,6 y 7,4 debido a que $\mathrm{pH}$ menores a 6,2 es un valor en el que la población bacteriana metanogénica disminuye.

La figura 4, presenta el comportamiento de los ST y SVT durante la primera etapa del arranque. Los sólidos en la fase 1 descienden desde el tercer día de digestión anaerobia. Durante esta fase, la carga

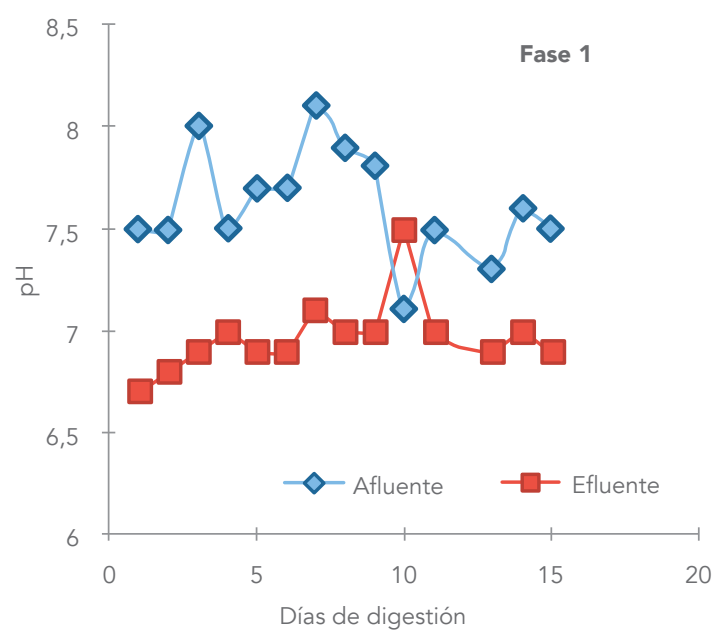

contaminante presente en el ARD, garantizó la materia orgánica disponible para las bacterias y por tanto su población se incrementó, generando un ascenso en la velocidad de sedimentación (Vs) y el tamaño de los gránulos, permitiendo así mayor compactación del manto de lodos y mayor retención de sólidos. Para la fase 2 , se observó un comportamiento diferente, pues desde el tercer día inicia un descenso en ST y SVT, sin embargo después del décimo día sufren un incremento, esto podría indicar que el caudal en esta fase y su respectivo TRH (25,28 h), ocasionan una sobresaturación de materia orgánica que no alcanza a ser metabolizada y con el paso de los días se ve reflejado en un lodo sin tamaño de gránulo adecuado, sin compactación y sin posibilidad de retención de ST.

Para los porcentajes de remoción de materia orgánica durante las fases 1 y 2 (Tabla 2), no se encontraron diferencias significativas. En ambos casos se supera en algo el $70 \%$ de remoción, sin embargo hay una mayor eficiencia en el sistema operado en la fase 2 con un TRH de algo más que un día. Se pudo observar perturbación de los porcentajes de remoción de materia orgánica al inicio de la digestión anaerobia cuando se cambian las condiciones

Figura 3. Comportamiento del pH en la primera etapa del arranque, fases 1 y 2 .

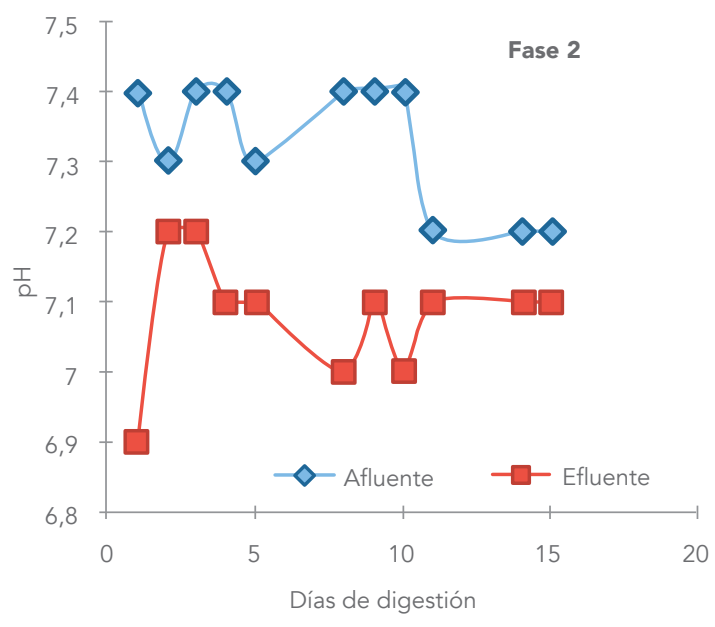



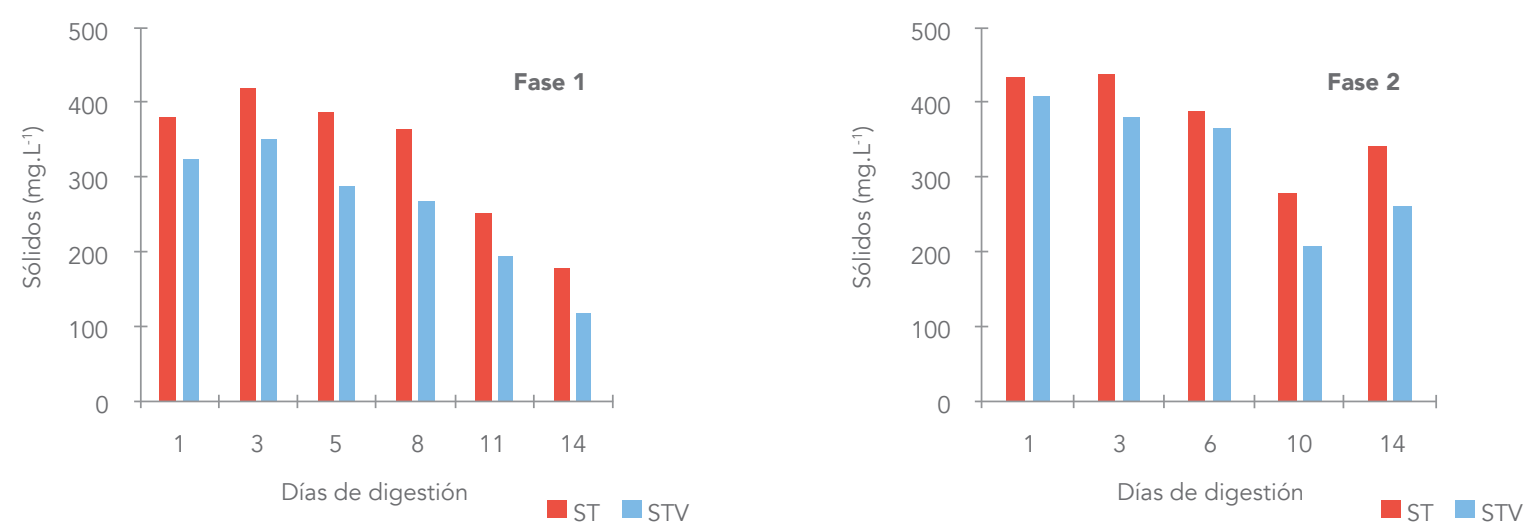

Figura 4. ST y SVT en el efluente del reactor durante la primera etapa del arranque

Tabla 3. Concentración promedio y eficiencia de remoción de DQO en la primera etapa del arranque.

Fase $1 \mathrm{THR}=38,34$ horas

\begin{tabular}{|c|c|c|c|c|c|c|c|c|}
\hline Parámetro & Afluente & Efluente & $\begin{array}{c}\% \\
\text { Remoción }\end{array}$ & $\begin{array}{l}\text { Tiempo de } \\
\text { digestión (d) }\end{array}$ & Afluente & Efluente & $\begin{array}{c}\% \\
\text { Remoción }\end{array}$ & $\begin{array}{c}\text { Tiempo de } \\
\text { digestión (d) }\end{array}$ \\
\hline \multirow{6}{*}{$\begin{array}{c}\text { DQO } \\
\left(\mathbf{m g} \cdot \mathrm{L}^{-1}\right)\end{array}$} & \multirow{6}{*}{$\begin{array}{c}282,84 \\
(4,0)\end{array}$} & 95,67 & 66,18 & 3 & \multirow{6}{*}{$\begin{array}{c}289,85 \\
(0,21)\end{array}$} & 120,70 & 58,36 & 3 \\
\hline & & 75,67 & 73,25 & 6 & & 116,60 & 59,77 & 5 \\
\hline & & 102,33 & 63,82 & 9 & & 78,00 & 73,09 & 9 \\
\hline & & 76,00 & 73,13 & 12 & & 75,00 & $74,12,85$ & 13 \\
\hline & & 81,22 & 71,28 & 15 & & 70,05 & 75,83 & 15 \\
\hline & & 79,00 & 72,07 & 18 & & 73,03 & 74,80 & 17 \\
\hline
\end{tabular}

Los valores en ( ) corresponden a la desviación estándar

operacionales del sistema (cambio de fase), esto es debido a que la población bacteriana se tiene que adaptar a nuevas condiciones.

En la Figura 5 se visualizan los resultados en escala log(10) de los análisis microbiológicos del ARD (Coliformes Totales y Coliformes Fecales) en el afluente y efluente del rector UASB en sus diferentes fases. Los resultados establecen que al iniciar la fase 1 , el afluente tiene una elevada carga bacteriana, reportándose una población de 7,66 log(10) de NMP al entrar al reactor y después del proceso anaerobio, se tienen una población de 6,66 log(10) de NMP de coliformes totales, indicando que se alcanzó una remoción bacteriana de un 13\%, debido a que el manto de lodo se estaba aclimatando al sustrato y al caudal. Al final de la primera fase e inicio de la 2, el porcentaje de remoción aumentó e igualmente al finalizarla se obtuvo un $29 \%$ de remoción en coliformes. El porcentaje de remoción de coliformes en la tercera fase disminuyó, producto del taponamiento ocasionado por la fluidización que se presentó del lodo. 

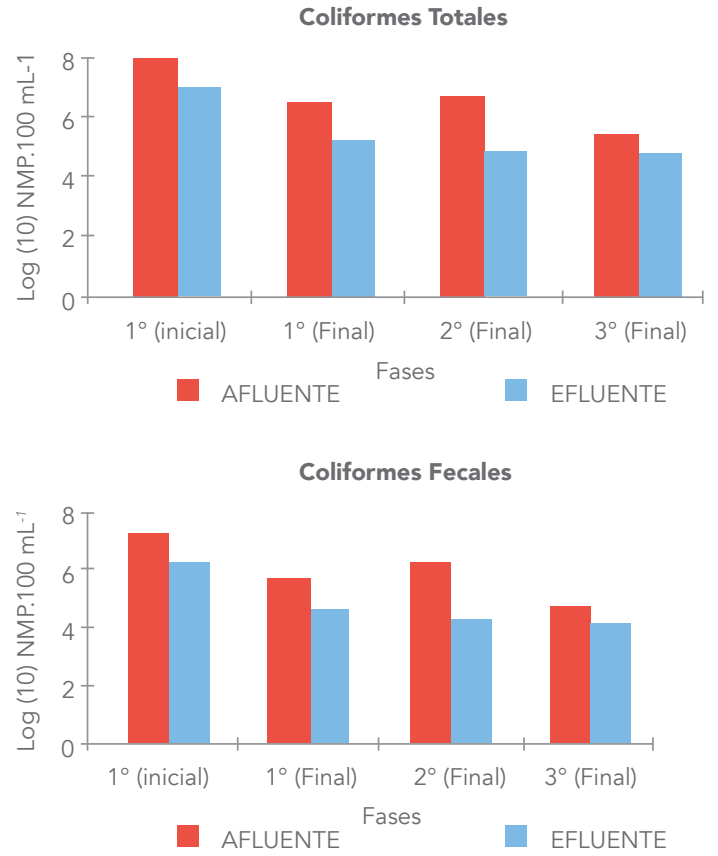

Figura 5. Coliformes totales y fecales durante la etapa 1 del arranque del reactor

\section{Segunda etapa del arranque}

A partir de los resultados obtenidos en la primera etapa de arranque, se seleccionó el caudal y TRH de la fase operacional 2, donde se podía garantizar un TRH de $25 \mathrm{~h}$, con porcentajes de remoción por encima del 73\%. En la segunda etapa se utilizó como afluente ARD con concentraciones de DQO alta y baja, con el fin de determinar la máxima carga que soporta el reactor y la máxima remoción de materia orgánica que alcanza.

El sistema anaerobio a concentración baja afectó la alcalinidad total y aumentó la alcalinidad parcial, la alcalinidad intermedia es cada vez mayor en los primeros días de digestión y la amortiguación buffer es menor a comparación de los resultados reportados cuando se trabajó el sistema a concentración media y alta (Tabla 2 y 4, Fig. 6). También el sistema comenzó a desestabilizarse, debido a que el pH en el efluente comenzó a decaer a medida que transcurrían los días de digestión (Fig. 7).
Tabla 4. Alcalinidad total, parcial e intermedia en la etapa 2 del arranque.

\begin{tabular}{|c|c|c|c|c|c|}
\hline \multicolumn{6}{|c|}{ Concentración Baja (mgCaCO$\left.{ }_{3} \cdot \mathrm{L}^{-1}\right)$} \\
\hline \multicolumn{3}{|c|}{ Afluente } & \multicolumn{3}{|c|}{ Efluente } \\
\hline AP & AT & Al & AP & AT & Al \\
\hline 88,125 & 157,5 & 69,375 & 38,125 & 62,5 & 24,375 \\
\hline 102 & 158 & 56 & 88,125 & 157,5 & 69,375 \\
\hline 75 & 119,375 & 44,375 & 51,25 & 88,75 & 37,5 \\
\hline 65 & 119 & 54 & 66,875 & 111,25 & 44,375 \\
\hline 68 & 124 & 56 & 71,9 & 119 & 47,1 \\
\hline 82 & 142 & 60 & 71 & 115 & 44 \\
\hline \multicolumn{6}{|c|}{ Concentración Alta $\left(\mathrm{mgCaCO}_{3} \cdot \mathrm{L}^{-1}\right)$} \\
\hline \multicolumn{3}{|c|}{ Afluente } & \multicolumn{3}{|c|}{ Efluente } \\
\hline AP & AT & Al & AP & AT & $\mathrm{Al}$ \\
\hline 83,75 & 131,25 & 47,5 & 88,125 & 146,25 & 58,125 \\
\hline 76,875 & 127,5 & 50,625 & 95 & 155 & 60 \\
\hline 79 & 128,9 & 49,9 & 96,25 & 153,75 & 57,5 \\
\hline 80 & 127,55 & 47,55 & 101,9 & 151,02 & 49,12 \\
\hline 88 & 130,4 & 42,4 & 118 & 164 & 46 \\
\hline 95 & 133 & 38 & 120 & 163 & 43 \\
\hline
\end{tabular}

Además, la relación Al/AT indicó que se está produciendo una mayor concentración de intermediarios de AGV lo cual evidenció una posible acidificación del sistema, por lo tanto se requirió adicionar, directamente al manto de lodos, $\mathrm{CaCO}_{3}$ (100 mg.L-1) de forma dosificada los días 6, 7 y 8 para poder estabilizar el sistema anaerobio.

A partir del día 12 el sistema comenzó a reaccionar positivamente y para garantizar su estabilidad se decidió el aumento en la concentración del sustrato (ARD a concentración alta de DOO) logrando así la corrección del sistema como lo muestran los 


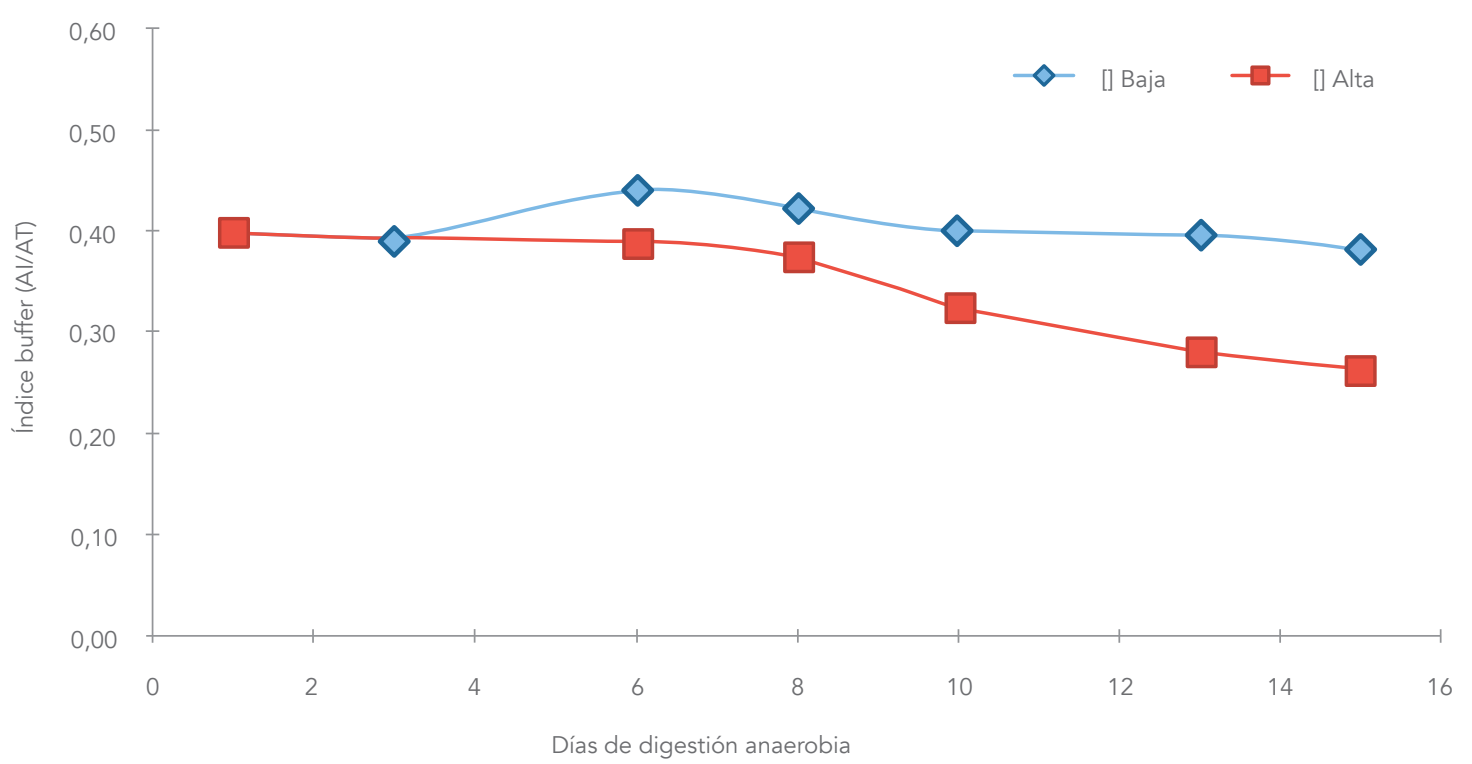

Figura 6. Capacidad tampón en el efluente de la digestión anaerobia a concentración baja y alta de DQO del sustrato.

resultados de índice buffer, $\mathrm{pH}$ y alcalinidad al cambiar la concentración del ARD (Tabla 4, Figuras 6 y 7).

El cambio de ARD a concentración alta mejoró los valores de $\mathrm{pH}$ de tal manera que el comportamiento del efluente a concentración alta de sustrato es similar al afluente (Figura 7).

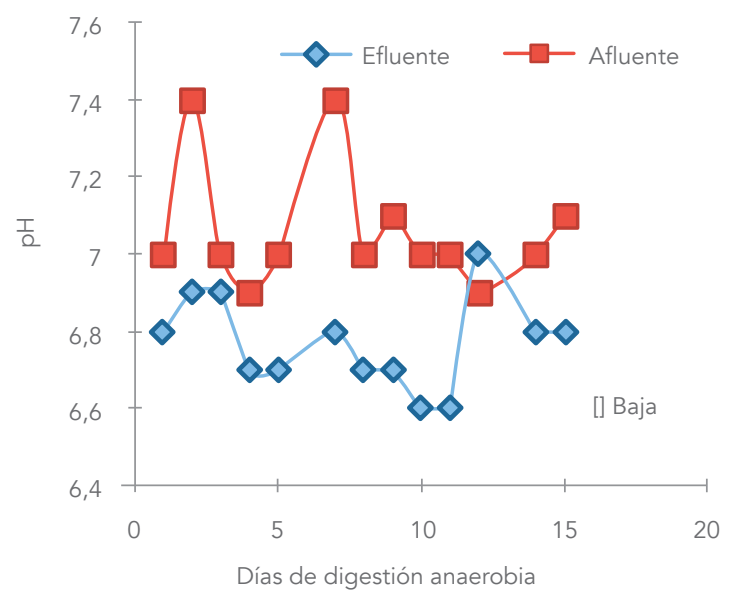

Figura 7. Comportamiento del pH en la segunda etapa del arranque
El descenso de los STV (Fig. 8) en el efluente, a concentración alta, principalmente desde el día 6, comprueba el proceso de digestión realizado por las bacterias anaerobias. Cuando se aumenta la concentración de ARD hay mayor material disponible para las bacterias presentes en el manto de lodos, por

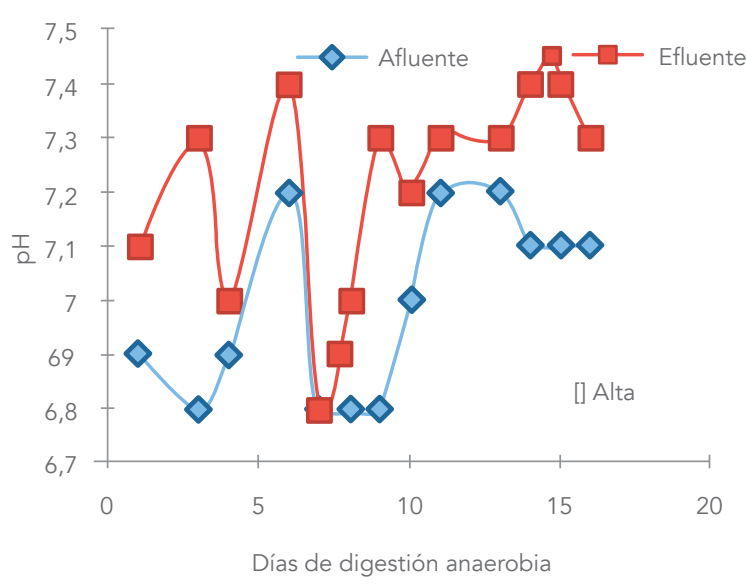


tanto se incrementa la retención de material orgánico y disminuye la concentración de sólidos en el ARD a medida que avanza la digestión anaerobia.

Caso contrario ocurre cuando se trabajó a concentración baja de DQO en el afluente (Fig. 8) donde los sólidos aumentaron a medida que prosiguió la digestión anaerobia producto del bajo material orgánico disponible en el ARD de entrada y por el descenso en el fenómeno de granulación, ocasionando una desestabilización en el manto de lodos como se mostrará más adelante en este escrito.
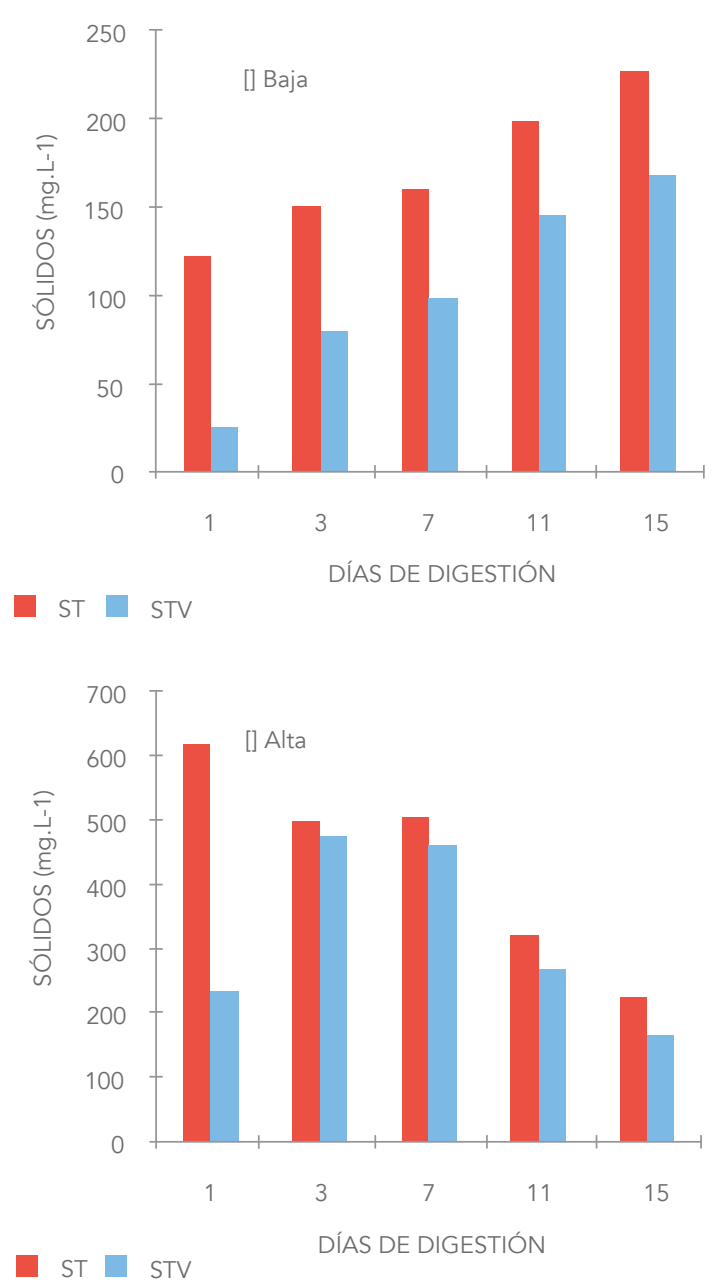

Figura 8. Comportamiento de ST y SVT en el efluente durante la segunda etapa del arranque
Los porcentajes de remoción de materia orgánica durante esta etapa a concentración baja y alta de ARD (Tabla 5) presentaron diferencias significativas. Cuando se cuenta con afluentes de alta concentración se mejora la respuesta en términos de remoción de DQO. Este resultado concuerda con la literatura reportada para este tipo de reactores, que son recomendados con altas eficiencias para AR con elevadas concentraciones de materia orgánica. En este trabajo, con estos resultados, se evidencia la posibilidad de implementarlos para ARD con mucho menos de 1000 mg. $\mathrm{L}^{-1}$ de DQO, sin control de temperatura y $\mathrm{pH}$.

Los resultados, en cuanto a número de coliformes totales y fecales, indican que en los primeros días del afluente con concentración baja, el porcentaje de remoción es del 11\%, producto de la desestabilización del lodo generada en la fase 3 de la primera etapa del arranque (Fig. 9). Pero al finalizar la concentración baja e inicios de la alta se presenta un incremento en la remoción de coliformes tanto totales como fecales (14\%), posiblemente debido al bajo material orgánico que se suministraba, pero al trabajar a una concentración alta de $\mathrm{DQO}$, se mejoró el porcentaje de remoción en el ARD hasta un 24\% en coliformes totales y un $23 \%$ en E. coli. En general, un efluente de un reactor UASB, o de un proceso anaerobio, no ofrece remociones importantes de microorganismos, éstos solo se ven disminuidos en procesos posteriores.

\section{Evolución del lodo anaerobio durante el periodo de arranque}

El seguimiento del comportamiento del lodo, se hizo durante aproximadamente 4 meses, tiempo que duró el proceso de arranque del reactor. Se analizaron muestras de lodo al inicio del proceso y al final de cada fase operacional (Fase 1 y 2 de la primera etapa y la segunda etapa que inicia con concentración baja del afluente y posteriormente con concentración alta). La Tabla 6 presenta los cambios en los sólidos y la AME del lodo. 
Tabla 5. Concentración promedio y eficiencia de remoción de DQO en la segunda etapa del arranque del reactor UASB.

\begin{tabular}{|c|c|c|c|c|c|c|c|c|}
\hline \multicolumn{5}{|c|}{ ARD a concentración baja } & \multicolumn{4}{|c|}{ ARD a concentración alta } \\
\hline & Afluente & Efluente & $\begin{array}{c}\% \\
\text { Remoción }\end{array}$ & $\begin{array}{l}\text { Tiempo de } \\
\text { digestión (d) }\end{array}$ & Afluente & Efluente & $\begin{array}{c}\% \\
\text { Remoción }\end{array}$ & $\begin{array}{l}\text { Tiempo de } \\
\text { digestión (d) }\end{array}$ \\
\hline \multirow{6}{*}{$\begin{array}{c}\mathrm{DQO} \\
\left(\mathrm{mg} \cdot \mathrm{L}^{-1}\right)\end{array}$} & \multirow{6}{*}{$\begin{array}{c}158,17 \\
(6,4)\end{array}$} & 70,67 & 55,32 & 3 & \multirow{6}{*}{$376(6,1)$} & 52,33 & 86,19 & 3 \\
\hline & & 62,32 & 60,60 & 6 & & 69,00 & 81,30 & 6 \\
\hline & & 60,50 & 61,75 & 9 & & 64,29 & 82,58 & 9 \\
\hline & & 58,60 & 62,95 & 12 & & 67,00 & 82,37 & 13 \\
\hline & & 59,80 & 62,19 & 15 & & 65,01 & 82,71 & 16 \\
\hline & & 60,00 & 62,06 & 17 & & 68,00 & 81,91 & 19 \\
\hline
\end{tabular}

Los valores en ( ) corresponden a la desviación estándar
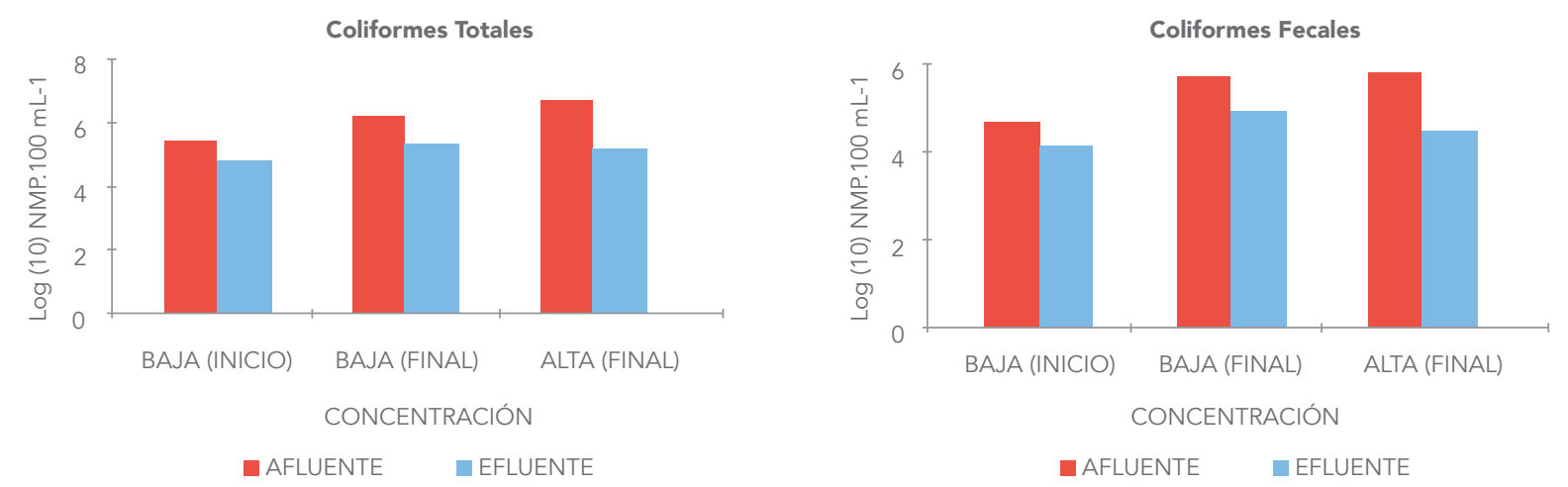

Figura 9. Coliformes totales y fecales en la segunda etapa del arranque

Tabla 6. Sólidos y AME del lodo anaerobio durante el arranque de reactor UASB.

\begin{tabular}{ccccc}
\hline \multirow{2}{*}{ Fases operacionales } & \multicolumn{3}{c}{ Sólidos $\left(\mathbf{m g}\right.$ L $^{-1}$ ) } & \multirow{2}{*}{ AME } \\
\cline { 2 - 4 } & ST & STV & STV/ST & \\
\hline Inicio & 88433 & 47183 & 0,534 & ---- \\
\hline Primera etapa: Fase 1 & 87425 & 43175 & 0,494 & 0,0238 \\
\hline Primera etapa: Fase 2 & 110940 & 39200 & 0,353 & 0,0232 \\
\hline Segunda etapa: concentración baja & 93568 & 31524 & 0,340 & 0,0183 \\
\hline Segunda etapa: concentración alta & 91762 & 28208 & 0,344 & 0,0235 \\
\hline
\end{tabular}


Durante el proceso anaerobio las bacterias producen mayor cantidad de energía en forma de metano que biomasa excesiva como subproducto (Fig. 10), por eso son tan atractivos estos sistemas en países subdesarrollados. La generación de energía que se produce en el reactor ocasiona un aumento lento de la biomasa; en los resultados que se muestran en la Tabla 6, no se pudo reflejar el incremento paulatino del lodo (ST), debido a que se extraían pequeñas cantidades de muestra por triplicado para los análisis pertinentes (30 g), afectando momentáneamente la altura del lodo mientras se garantizaba su altura con inoculo nuevo, produciendo problemas de adaptación en el manto de lodos por parte del nuevo inoculo. Una vez que se fue adaptando el manto de lodos al sistema, se observa un aumento de sólidos totales principalmente cuando finalizaron la fase 2 de la primera etapa y la segunda etapa con concentración alta de sustrato.

El fallo producido en la fase 3 de la primera etapa y después la utilización de ARD a concentración baja generó una desestabilización en el sistema, pues se acercó a la acidificación del mismo, como lo corroboran los otros parámetros indicadores (alcalinidad, $\mathrm{pH}$ y AME), lo cual generó disminución de biomasa activa según la relación STV/ST.

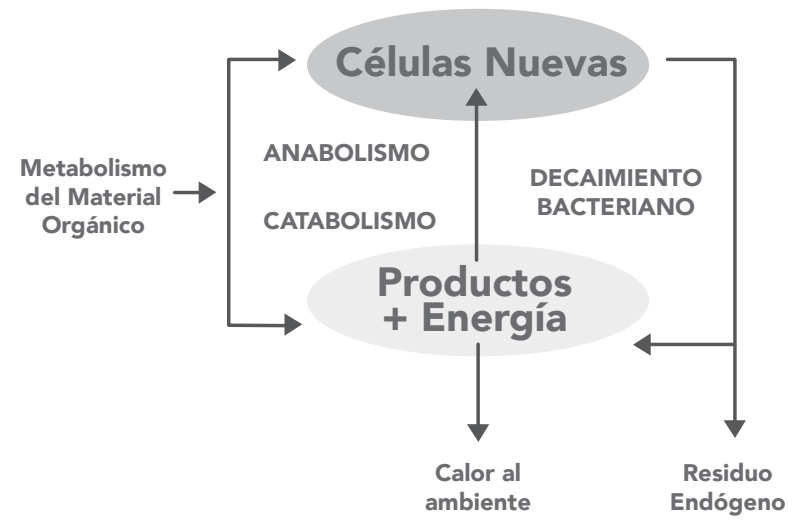

Figura 10. Representación esquemática del metabolismo bacteriano (Molina, 2012).
Según Torres et al (2004), la AME presente en lodos anaerobios de digestores oscila entre 0,020,2 gr DQO.gr ${ }^{-1}$ STV*d y para estiércol digerido entre 0,02-0,08 de AME, por tanto los resultados que se obtuvieron en nuestra investigación se encuentran en rangos establecidos en la literatura debido a que el lodo anaerobio utilizado es una mezcla entre lodo de estiércol de vaca y lodo proveniente de un digestor anaerobio.

Los resultados demuestran que a mayor concentración de DQO en el afluente, hay mayor producción de metano y por ende mayor AME (Tabla 5 y 6).

Según Ghangrekar et al. (2005), sugiere que entre mas bajo sea el IVL y mayor sea el tamaño del gránulo, mejor es la velocidad de sedimentación en el lodo, generando un mayor tiempo de retencion de solidos en la biomasa anaerobia. De acuerdo a Morillo y Fajardo (2005) y los resultados que se obtuvieron en la caracterización del lodo (Tabla 7), se puede decir, que la velocidad de sedimentación estuvo alrededor de 3-4 m.h-1 ${ }^{-1}$ lo cual nos indica que es un tipo de lodo floculante. Además, se visualiza que a medida que pasan los días de digestión anaerobia se incrementa la velocidad de sedimentación y el tamaño de los gránulos y el IVL disminuye.

En la Tabla 7, se observa que los coliformes en el lodo van en aumento, posiblemente se deba a que algunas de las bacterias que se encontraban en el ARD quedaban atrapadas en el lodo; pero en la fase 3 de la primera etapa, se visualiza una caída asociada a que el reactor UASB no soportó la carga hidráulica suministrada, desplazando pequeñas cantidades de lodo con el efluente.

Una vez superado el incide se puede apreciar un incremento paulatino de los coliformes en el manto de lodos, el cual aumentó considerablemente cuando se trabajó con un ARD más concentrada (280-300 mg. $\left.\mathrm{L}^{-1}\right)$. 
Tabla 7. Resultados de análisis del lodo anaerobio durante todo el proceso de arranque en reactor UASB.

\begin{tabular}{ccccccc}
\hline \multirow{2}{*}{ Parámetros } & Inicio & \multicolumn{3}{c}{ Primera etapa } & \multicolumn{2}{c}{ Segunda etapa } \\
\cline { 2 - 7 } & Fase 1 & Fase 2 & Fase 3 & Conc. Baja & Conc. Alta \\
\hline Granulometría (mm) & 0,123 & 0,165 & 0,245 & 0,186 & 0,218 & 0,313 \\
\hline $\begin{array}{c}\text { Coliformes Totales } \\
(\mathrm{NMP} / 100 \mathrm{ml})\end{array}$ & 230000 & $1,60 \mathrm{E}+06$ & $7,90 \mathrm{E}+06$ & $4,90 \mathrm{E}+06$ & $7,00 \mathrm{E}+06$ & $9,40 \mathrm{E}+06$ \\
\hline $\begin{array}{c}\text { Coliformes Fecales } \\
(\mathrm{NMP} / 100 \mathrm{ml})\end{array}$ & 90000 & $2,20 \mathrm{E}+05$ & $3,30 \mathrm{E}+06$ & $1,10 \mathrm{E}+06$ & $1,40 \mathrm{E}+06$ & $4,60 \mathrm{E}+06$ \\
\hline $\begin{array}{c}\text { Velocidad de } \\
\text { Sedimentación }\left(\mathrm{m} \cdot \mathrm{h}^{-1}\right)\end{array}$ & 2,995 & 3,159 & 3,134 & 2,631 & 2,670 & 3,135 \\
\hline $\begin{array}{c}\text { Índice Volumétrico de } \\
\text { Lodos (ml.g-1) }\end{array}$ & - & 6,790 & 6,197 & - & 7,595 & 6,675 \\
\hline
\end{tabular}

\section{CONCLUSIONES}

Es factible dar arranque a un reactor UASB bajo condiciones andino-amazónicas, con temperatura ambiente oscilante entre 24 y $32{ }^{\circ} \mathrm{C}$ y humedad relativa promedio del $84 \%$. Los porcentajes de remoción que se alcanzan superan el $80 \%$ cuando se alimenta el reactor con ARD que presenten $\mathrm{DQO}$ alrededor de $376 \mathrm{mg} \cdot \mathrm{L}^{-1}$, con un TRH mayor o igual a $25,28 \mathrm{~d}$. Se evidencia la posibilidad de implementar este proceso en AR (afluente) con DQO menores a $1000{\mathrm{mg} . \mathrm{L}^{-1}}^{-1}$ que es la concentración mínima, según la literatura, para obtener remociones óptimas de la materia orgánica. La concentración baja del ARD (DQO menor a $250 \mathrm{mg}^{\left.\mathrm{L}^{-1}\right)}$ ocasionó tendencia a la acidificación del sistema con el descenso de la capacidad buffer y poca granulación del lodo. Con la implementación de un caudal de $246,9 \mathrm{~mL} . \mathrm{h}^{-1}$, el reactor colapsó, de tal forma que se fluidizó el lodo ocasionando pérdida de biomasa activa según la relación STV/ST y desestabilización operacional.

\section{AGRADECIMIENTOS.}

Los autores agradecen a la Vicerrectoría de Investigaciones de la Universidad de la Amazonia por financiar este proyecto; al personal de laboratorios de química y de biología por el apoyo en los análisis y al taller de mecánica fina de la misma universidad por la construcción del reactor UASB. 


\section{REFERENCIAS}

1. APHA-AWWA-WPCF. 1998. Standard methods for examination of wáter and wastewater 20th Ed .American Public Health Association/American water Works, Washington,D.C.USA.

2. Cajigas A, Pérez A, y Torres P. 2005. Importancia del $\mathrm{pH}$ y la alcalinidad en el tratamiento anaerobio de las aguas residuales del proceso de extracción de almidón de yuca. Revista Scientia et technica, 1:243-248.

3. Camacho F, Giles A, Ortegón M, Palao B, Serrano $O$ y Velásquez. 2009. Método para la determinación de bacterias coliformes, coliformes totales y Escherichia Coli por la técnica de disoluciones en tubo múltiple (Número más probable o NMP). http://depa.fquim.unam.mx/ amyd/archivero/TecnicBasicas-Colif-tot-fecales-Ecoli-NMP_6529.pdf, consulta Abril 2013.

4. Chong S, Kanti T, Kayaalp A, y Ming H. 2012. The performance enhancements of upflow anaerobic sludge blanket ( UASB ) reactors for domestic sludge treatment e A State-of-theart review. Water Research, 46:3434-3470.

5. Corpoamazonia. 2002. Tratamiento de aguas residuales. Corporación para el desarrollo sostenible del Sur de la Amazonia. Municipio de Florencia. http://www.corpoamazonia.gov.co/. Consulta Abril del 2013.
6. Diaz-Baez M, Espitia S y Molina F. 2002. Digestión Anaerobia-una aproximación a la tecnología. UNIBIBLOS, Bogotá, D.C, 167 p.

7. Ghangrekar M, Asolekar S y Joshi S. 2005. Characteristics of sludge developed under different loading conditions during UASB reactor start-up and granulation. Water research, 39(6):1123-33.

8. Hulshoff L, De Castro S, Lettinga G, y Lens P. 2004. Anaerobic sludge granulation. Water Research, 38 (6):89-1376.

9. Instituto SINCHI (2006). Caracterización y tipificación de sistemas productivos y su impacto ambiental en el Caquetá. Bogotá,D.C.

10. Lahav O, Shlafman E, Morgan B, Loewenthal $R$, y Tarre S. 2002. Accurate on-site volatile fatty acids (VFA) measurement in anaerobic digestion-verification of a new titrative method. ProCeedings VII Latin American Workshop and Symposium on Anaer- Obic Digestion, Merida, Mexico, 118-125.

11. Molina F, Garcia C, Roca E y Lema J,. 2008. Characterization of anarobic granular sludge developed in UASB reactors that treat etanol, carbohydrates and hydrolyzed protein based wastewaters.Journal Water science and technology, 57(6):837-42 p. 
12. Molina F, Ruiz-Filippi G, Garcia C, Lema J, y Roca E. 2009. Pilot-Scale Validation of a New Sensor for On-Line Analysis of Volatile Fatty Acids and Alkalinity in Anaerobic Wastewater Treatment Plants, Journal Environmental Engineering Science, 26: 641-649.

13. Molina F. 2007. Comportamiento dinámico de digestores anaerobios. Trabajo de grado, Departamento de ingeniería química. Universidad Santiago de Compostela. Santiago de Compostela, España., 250 p.

14. Molina F. 2012.Conferencia (Ponencia). Ingeniería de la digestión anaerobia y purificación del agua residual. Curso sobre tecnologías anaerobias para la depuración de aguas residuales en el contexto Latinoamericano. Grupo de investigación en Gestión y Modelación Ambiental-GAIA Universidad Nacional de Colombia, Manizales, Colombia.

15. Morillo y Fajardo. 2005. Tesis. Estudio de los reactores UASB para el tratamiento de lixiviados del relleno la esmeralda. Facultad de ingeniería y arquitectura. Universidad Nacional de Colombia,Manizales.,84 p.

16. Pérez A y Torres P. 2010. Actividad Metanogénica específica: Una herramienta de control y optimización de sistemas de tratamiento anaerobio de aguas residuales. Ingeniería de Recursos Naturales y del Ambiente, 9: 5-14.

17. Pérez A, y Torres P. 2008. Índices de alcalinidad para el control del tratamiento anaerobio de aguas residuales fácilmente acidificables. Sanitary Engineering, 52: 41-52.

18. Seghezzo L. 2004. Anaerobic treatment of domestic wastewater in subtropical regions. Trabajo de Grado. Wageningen University. Wageningen, the Netherlands., $190 \mathrm{p}$.

19. Torres M L, Villa PM, y Escobedo R. 2004. El comportamiento de reactores anaerobios de residuos sólidos a través de ensayos microbiológicos. Revista Centro Nacional de Investigaciones Científicas (CENIC), 35: 179-183.

20. Torres P. 2012. Perspectivas del tratamiento anaerobio de aguas residuales domésticas en países en desarrollo. Revista Escuela de Ingeniería de Antioquia (EIA), 18: 115-129.

21. Turkdogan F, Yetilmezsoy F, Comez S. 2011. Effect of extracellular enzyme activity on digestion performance of mesophilic UASB reactor treating high-strength municipal wastewater. Bioprocess \& Biosystems Engineering, 34: 389-401. 